\title{
Adsorption of Brilliant Green onto Luffa Cylindrical Sponge: Equilibrium, Kinetics, and Thermodynamic Studies
}

\author{
Olaseni Segun Esan, ${ }^{1}$ Oladoja Nurudeen Abiola, ${ }^{1}$ Olanrewaju Owoyomi, ${ }^{2}$ \\ Christopher Olumuyiwa Aboluwoye, ${ }^{1}$ and Medinat Olubunmi Osundiya ${ }^{1}$ \\ ${ }^{1}$ Chemistry Department, Adekunle Ajasin University, P.M.B 001, Akungba-Akoko, Nigeria \\ ${ }^{2}$ Department of Chemistry, Obafemi Awolowo University, P.M.B 432, Ile Ife, Nigeria
}

Correspondence should be addressed to Olaseni Segun Esan; lincolnolaseni@yahoo.com

Received 27 November 2013; Accepted 19 January 2014; Published 4 March 2014

Academic Editors: J. J. Lopez Cascales, L. K. Shrestha, and N. A. Vodolazkaya

Copyright (C) 2014 Olaseni Segun Esan et al. This is an open access article distributed under the Creative Commons Attribution License, which permits unrestricted use, distribution, and reproduction in any medium, provided the original work is properly cited.

\begin{abstract}
The sponge of Luffa cylindrical (LFC), a fibrous material, was employed as adsorbent for the removal of Brilliant Green (BGD) from aqueous effluent via batch studies. The optimum removal of BGD was found at $\mathrm{pH} 8.2$ and the equilibrium was attained within 3 hours. The kinetic data are analyzed using several models including pseudo-first-order, pseudo-second-order, power function, simple elovich, intraparticle diffusion, and liquid film diffusion. The fitting of the different kinetics models to the experimental data, tested by error analysis, using the linear correlation coefficient $\left(r^{2}\right)$ and chi-square analysis $\left(\chi^{2}\right)$, showed that the mechanism of adsorption process was better described by pseudo-second-order and power function kinetic models. The equilibrium isotherm data were analyzed using Langmuir, Freundlich, and Temkin models and the sorption process was described by the Langmuir isotherm with maximum monolayer adsorption capacity of $18.2 \mathrm{mg} / \mathrm{g}$ at $303 \mathrm{~K}$. The thermodynamic properties $\Delta G^{0}, \Delta H^{0}$, and $\Delta S^{0}$ showed that adsorption of BGD onto LFC was spontaneous, endothermic, and feasible within the temperature range of 303-313 K.
\end{abstract}

\section{Introduction}

Worldwide, over $7 \times 10^{5}$ tons of dyes and pigments are produced annually [1] and an estimated $90 \%$ of this ends up on fabrics [2]. Due to the development of textile, printing, and tanning industries, large amounts of dye water waste are produced [3]. The textile industry alone accounts for twothird of the total dye stuff production and about 10 to $15 \%$ of the used dyes come out through the effluent [4]. Wastewater containing dyes is difficult to treat, since the dyes are recalcitrant organic molecules, resistant to aerobic digestion and are stable to light, heat, and oxidizing agents [5]. Efficient color removal from wastewaters is, therefore, of high importance, and so in recent years, it has attracted increased research and technological interest, involving physical and/or chemical methods (i.e., coagulation/flocculation) [6], adsorption [7], oxidation [8], and membrane based separation [9-11].

Amongst all these treatment methods, adsorption is the most appropriate and efficient technique for the removal of nonbiodegradable pollutants (including dyes) from waste water $[12,13]$. Although many adsorbents have been reported for removing some common dyes [14-19], such as methyl orange, methylene blue, Congo Red, and Brilliant Green (Figure 1), activated carbon has proven to be the most widely used adsorbent for the removal of dye but this has been restricted due to regeneration problem and high cost [20].

Recently, researchers have focused on the development of cheaper, nonconventional, low-cost adsorbents as an alternative to activated carbon. Some of these include powdered peanut [21], bagasse fly ash [22], palm kernel coat [23], and raw pine cone [24].

Brilliant Green (BGD) which appears as golden crystal is an organic dye that belongs to the family of triphenylmethane [25] and has been used for various purposes, for example, biological stain, dermatological agent, veterinary medicine, and an additive to poultry feed to inhibit propagation of mold, intestinal parasites, and fungus [19]. This dye is known to be toxic to humans and animals when injected. It causes irritation to the gastrointestinal tract and upon prolonged exposure resulted in organ damage [26]. Upon decomposition of 


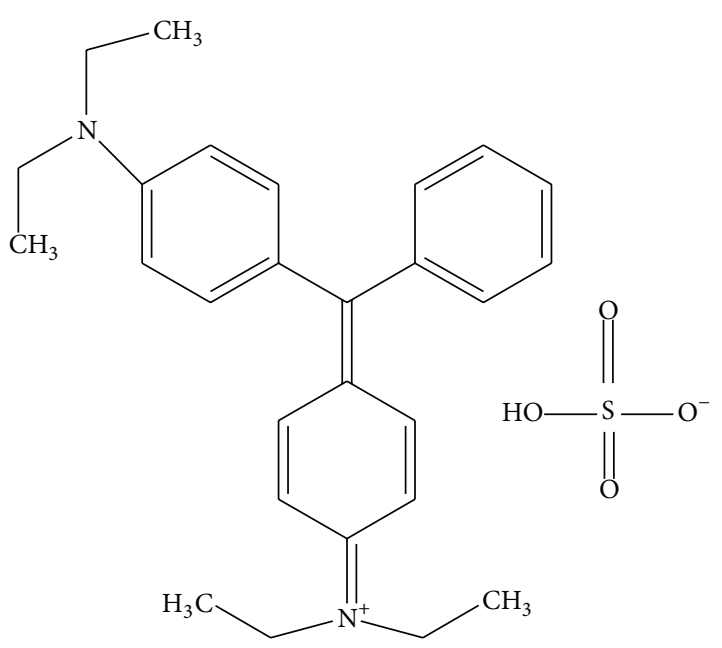

FIgURE 1: Brilliant Green.

this dye, carbon dioxide, sulphur oxides, and nitrogen oxides are produced [27].

Luffa cylindrical (LFC) belongs to the Cucurbitaceae family [28] and is commonly grown in China, Japan, Nigeria, and countries in central and South America. LFC sponge is composed mainly of cellulose, hemicelluloses, and lignin [29]. On this note, LFC is called lignocelluloses material. Because it has a fibrous vascular system that can allow the removal of water pollutants. Various researchers utilized Luffa cylindrical in different forms to remove dyes from solution. Like Ola [30] used luffa activated carbon, Demir et al. [29] used $\mathrm{NaOH}$ treated luffa and Oladoja et al. [17] used untreated luffa to remove dyes from solution.

Owing to the toxicity of BGD dye, it is essential to remove BGD from waste water. Early, Bhattacharyya and Sarma [31] have used finely ground neem leaf, Kismir and Aroguz [27] used saklikert mud, Mittal et al. [26] used bottom ash and deoiled soya, and Mane et al. [32] used rice husk ash as lowcost adsorbent for removing BGD from aqueous media. In the present study, Luffa cylindrical powder shall be studied as adsorbent for BGD removal.

However, this study is detailed to investigate the possibility of utilizing LFC for the removal of BGD from aqueous solution by performing batch studies. The effect of different experimental conditions, such as contact time, initial $\mathrm{pH}$, initial dye concentration, and temperature were investigated, and the adsorption mechanism was examined using kinetic and thermodynamic studies.

\section{Materials and Methods}

2.1. Sorbent Preparation. LFC was obtained locally from Akungba-Akoko, the University town, Nigeria. The LFC was dehusked and the intervening tissue was removed [17] while the LFC fibers were washed with water to remove all the water soluble contaminant, until the washing became clear, and dried in the oven at $70^{\circ} \mathrm{C}$ for $6 \mathrm{~h}$ [29]. The dried LFC fibers were ground with Laboratory blender and screened through a set of sieves to obtained particles of size $100 \mu \mathrm{m}$.

2.2. Dye Solution and Reagents. BGD [Sulfate of N,N-diethylaniline] is a cationic dye classified as C.I. basic green 1; (C.I. 42040; FW: 462.65 and $625 \mathrm{~nm} \lambda_{\max }$ ) was obtained from Fine Chemical, Mumbai, India and used without further purification. Stock solution, $(500 \mathrm{mg} / \mathrm{L})$, was prepared and working solutions were prepared from the stock by serial dilution. The $\mathrm{pH}$ of the solution was adjusted when required by adding drops of $\mathrm{HCl}(1.0 \mathrm{M}$ or $0.1 \mathrm{M})$ or $\mathrm{NaOH}(1.0 \mathrm{M}$ or $0.1 \mathrm{M})$ solutions. Changes were monitored with a $\mathrm{pH}$ meter (Jenway, model 710, USA).

2.3. Dye Quantification. The BGD concentration in aqueous solution was quantified by the determination of the optical density at the characteristic wavelength using a double beam $\mathrm{UV} /$ visible spectrophotometer. A standard solution of the dye was taken and the optical density was determined at different wavelength to obtain a plot of optical density versus wavelength. The wavelength corresponding to the maximum optical density $\left(\lambda_{\max }=625 \mathrm{~nm}\right)$, as determined from this plot, was noted and the wavelength was used for the preparation of the calibration curve used in the present studies.

\subsection{Characterization of Adsorbent (LFC)}

2.4.1. Point of Zero Charge (PZC) Determination and FTIR Study. The $\mathrm{pH}_{\mathrm{ZPC}}$ shows considerable usage for the determination of surface electrical neutrality at a definite $\mathrm{pH}$ value. The determination of zero point charge $\left(\mathrm{pH}_{\mathrm{ZPC}}\right)$ was done via the solid addition method [33]. Possible involvement of functional groups from LFC during the removal of BGD from aqueous solution was elucidated using the Fourier transform infrared (FTIR) analysis. FTIR spectra were obtained on a PerkinElmer FTIR-600 spectrometer. The analysis conditions used were 16 scans at a resolution of $4 \mathrm{~cm}^{-1}$ measured between 400 and $4000 \mathrm{~cm}^{-1}$.

2.5. Adsorption Experiments. Batch adsorption experiment studies were conducted by agitating $0.1 \mathrm{~g}$ of adsorbent with $50.0 \mathrm{~mL}$ of BGD solution of the desired initial dye concentration of $20-200 \mathrm{mg} / \mathrm{L}$ in a $250 \mathrm{~mL}$ stoppered conical flask. The mixture was agitated in a temperature controlled orbital shaker at a constant speed of $160 \mathrm{rpm}$ at required temperature. Samples were withdrawn at regular interval and centrifuged and the residual BGD concentration was calculated from the calibration curve [34]. The kinetics of adsorption was conducted by analyzing adsorptive uptake of the dye from the aqueous solution at different time intervals $(2,5,10,30$, $60,90,120$, and $180 \mathrm{~min})$. For studying the effect of solution $\mathrm{pH}$ on dye adsorption, experiment was conducted at different $\mathrm{pH}$ varying from 4.2 to 9.3 for initial dye concentration of $200 \mathrm{mg} / \mathrm{L}$. To observe the effect of temperature on dye adsorption, sorption characteristic was investigated by determining the adsorption isotherms at $303,313,323$, and $333 \mathrm{k}$. The amount of sorbate sorbed per unit mass of the LFC 
( $q_{t}$ in $\mathrm{mg} / \mathrm{g}$ ) and percentage dye removal efficiency, $R$, was calculated using the mass balance procedure as follows:

$$
\begin{gathered}
q_{t}=\frac{\left(C_{0}-C_{t}\right) V}{M}, \\
R=\left(\frac{C_{0}-C_{t}}{C_{0}}\right) \cdot 100,
\end{gathered}
$$

where $C_{0}$ is the initial dye concentration $(\mathrm{mg} / \mathrm{L}), C_{t}$ is the concentration of dye at any time $t, V$ is the volume of solution in (L), and $M$ is the mass of BGD (g).

2.6. Error Analysis. In the present study, each of the isotherm models was tested using the linear coefficient of determination, $r^{2}$, and the chi-square statistical method, $\chi^{2}$. The coefficient of determination, $r^{2}$, represents the percentage of variability in the dependents variable that has been explained by regression line. The value of the coefficient of determination may vary from zero to one. The linear coefficient of determination, $r^{2}$, found from evaluation of data by linear model, was calculated with the aid of the following equation:

$$
r^{2}=\frac{S_{x y}^{2}}{S_{x x} S_{y y}},
$$

where $S_{x x}$ is the sum of squares of $x, S_{y y}$ is the sum of square of $y$, and $S_{x y}$ is the sum of squares of $x$ and $y$.

In order to evaluate the best of the isotherm models that fit the experimental data, the sorption process was also examined using nonlinear chi-square statistical test. The chisquare statistic test is basically the sum of the squares of the differences between the experimental data and data obtained by calculating from models, with each squared difference divided by the corresponding data obtained by calculating from models. The equivalent mathematical statement is

$$
\chi^{2}=\frac{\sum\left(q_{e, \exp }-q_{e}\right)^{2}}{q_{e}} .
$$

If data from model are similar to the experimental data, then $\chi^{2}$ will be a small number, and if they are different, $\chi^{2}$ will be a bigger number.

\section{Result and Discussion}

3.1. Results of Point of Zero Charge $\left(\mathrm{pH}_{P Z C}\right)$ Determination and FTIR Analysis. The point of intersection of $\Delta \mathrm{pH}$ versus $\mathrm{pH}_{0}$ showed that the $\mathrm{pH}_{\mathrm{ZPC}}$ of LFC occurred at $\mathrm{pH} 5.2$ as shown in Figure 2. This showed that at $\mathrm{pH}$ less than 5.2 the surface of LFC is predominated by positive charges while at $\mathrm{pH}$ greater than 5.2 , the surface is predominated by negative charges.

It was clear from Figures 3 to 4 that FTIR spectra of the LFC before and after adsorption of BGD displayed a number of absorption peaks, reflecting the complex nature of the material examined. They are carbonyl and hydroxyl groups, on the surface of LFC from FTIR analysis [35]. The broad absorption peaks around $3423 \mathrm{~cm}^{-1}$ were indicative

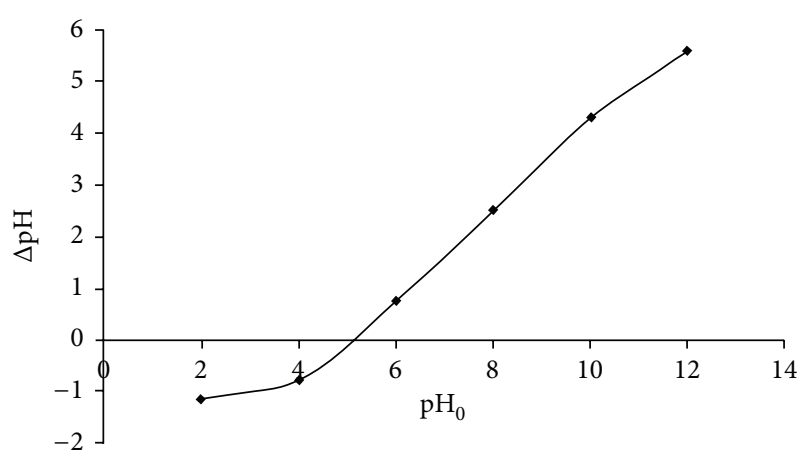

FIGURE 2: Results of the determination of the $\mathrm{pH}_{\mathrm{ZPC}}$.

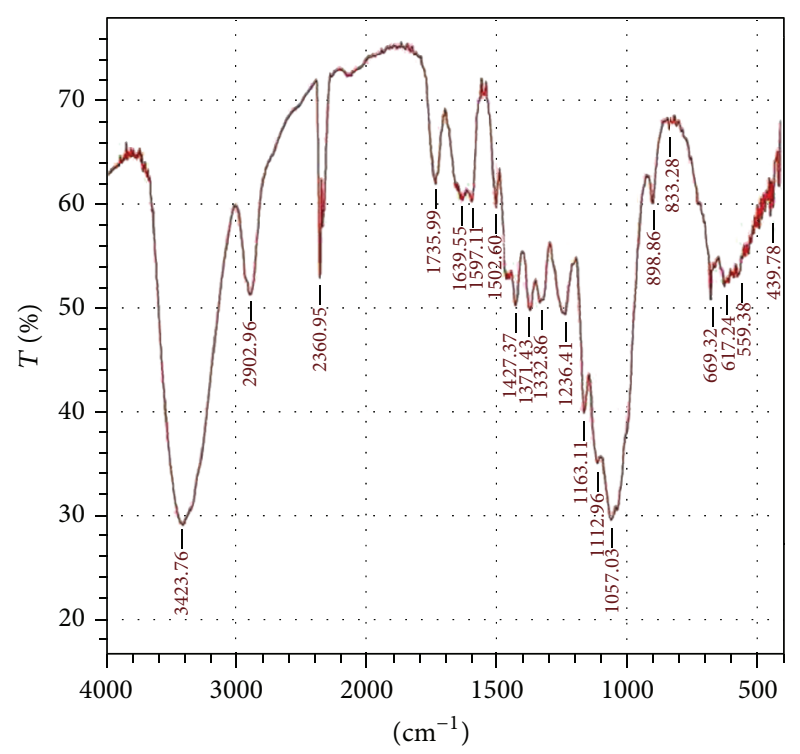

FIGURE 3: FT-IR of Luffa cylindrical (LFC) before adsorption of BGD.

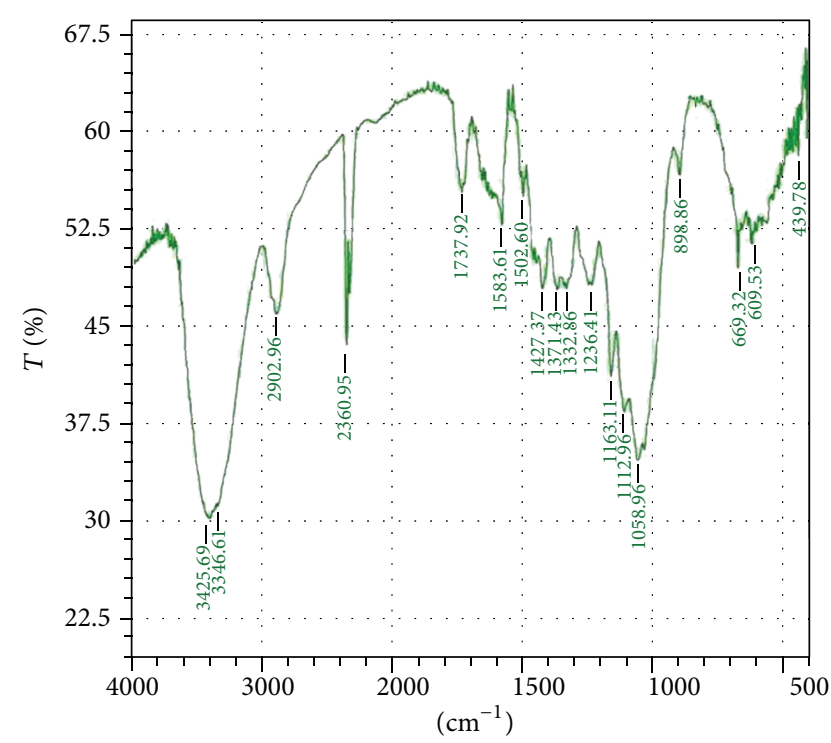

FIGURE 4: FT-IR of Luffa cylindrical (LFC) after adsorption of BGD. 
of existence of bonded hydroxyl groups on the surface of LFC. The peaks at 2902 and $2360 \mathrm{~cm}^{-1}$ were assigned to the stretching vibration and bending vibration of $\mathrm{C}-\mathrm{H}$ bond in methylene group, respectively. The broad band at $1735 \mathrm{~cm}^{-1}$ was assigned to the carbonyl and carbonyl moieties $(\mathrm{C}=\mathrm{O})$. The peaks associated with the stretching vibration in aromatic rings were verified at 1597 and $1425 \mathrm{~cm}^{-1}$. The peak at $1236 \mathrm{~cm}^{-1}$ was assigned to the bending vibration of carboxylic groups while deformation related to $\mathrm{C}-\mathrm{O}$ bond was observed at $1057 \mathrm{~cm}^{-1}$ which also confirmed the lignin structure of the LFC. All of these surface functional groups of the LFC can interact with the BGD molecules. Thus, the adsorption of BGD on LFC may be attributed to (i) chemical interaction between surface functional groups and BGD molecules (ii) electrostatic interaction between the BGD molecules and electron-rich sites on the LFC surface, and (iii) week physical forces, mainly hydrogen bonding and van der Waals interactions between the BGD molecules and the LFC. Therefore, the adsorption of BGD onto LFC surface may emanate from the interaction between the carboxyl group of LFC and the electronegative groups in BGD, hydrogen bonding between the hydroxyl group of LFC and the nitrogen of the BGD molecules, and hydrogen bonding between the hydroxyl group of the LFC and the aromatic ring in the BGD molecule. This has confirmed that adsorption of BGD onto LFC follows a complicated pattern which involved both physical and chemical.

3.2. Effect of pH on the Adsorption Capacity. It is a known fact that solution $\mathrm{pH}$ is an important variable in sorption studies. The $\mathrm{pH}$ of the solution affects surface charge of the adsorbent, the degree of ionization of adsorbate molecule, and extent of dissociation of functional groups on the active sites of the adsorbent [19]. The dye uptake variations at different $\mathrm{pH}$ value and initial concentrations of $200 \mathrm{mg} / \mathrm{L}$ are shown in Figure 5. The adsorption rate changed at the beginning, from $11.5 \%$ at $\mathrm{pH} 2.0$ to $89.9 \%$ at $\mathrm{pH} 6.97$. With a further increase of $\mathrm{pH}$ from 6.97 to 10.0, the adsorption rate decreased. Consequently, $\mathrm{pH} 6.97$ was selected as the operating $\mathrm{pH}$ for subsequent studies.

The possible explanations are as follows. (i) LFC has an estimated point of zero charge of $\mathrm{pH} 5.2$, above which LFC surface is predominantly negatively charge, leading to a favorable electrostatic interaction between the cationic BGD molecule and the LFC, hence there is a linear increase in BGD uptake as shown in Figure 5. (ii) In an acidic and at lesser alkaline medium, the $\mathrm{Cl}^{-}$and $\mathrm{OH}^{-}$from $\mathrm{HCl}$ and $\mathrm{NaOH}$ destroy the conjugated bond present in the aromatic rings of the dye molecule upon which the BGD structure changed and result in the formation of colorless compound [36], leading to increase in the uptake of BGD molecule from solution as shown in Figure 5. (iii) The presence of carboxyl groups on the surface of LFC, as confirmed by Figures 3 and 4 also, enhances sorption of BGD with increase in $\mathrm{pH}$ from 2 to 8 and later decrease at $\mathrm{pH} 10$. This is because the $\mathrm{pk}_{\mathrm{a}}$ value of carboxyl groups lies within the range of 3.8-5.0 [37]. Below $\mathrm{pH}$ 5.0, the carboxyl group on the surface of LFC gets protonated $\left(\mathrm{H}^{+}\right)$making the number of positive charge sites

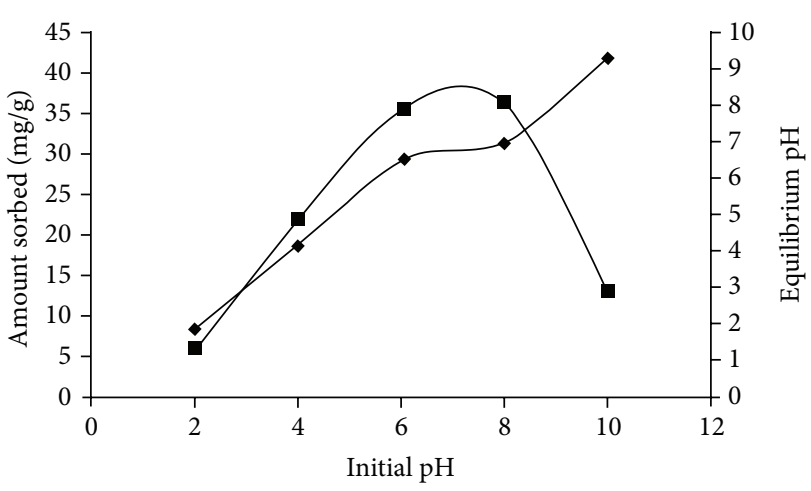

FIGURE 5: Effects of initial solution $\mathrm{pH}$ on the sorption of BGD onto LFC.

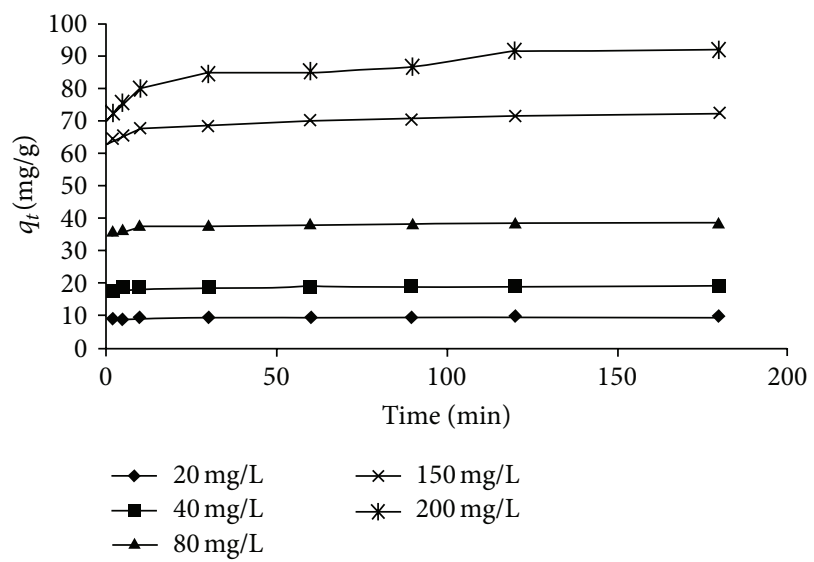

FIGURE 6: Effect of contact time on the removal of BDG onto LFC.

increase and the number of negative charge decrease resulting in electrostatic repulsion, hence decrease in BGD uptake by LFC. With an increase in $\mathrm{pH}$ of the solution, these functional groups became deprotonated $\left(\mathrm{COO}^{-}\right)$, which resulted in an increase in the negative charge density on the LFC surface and facilitated the binding of BGD dyes [38]. Hence, the BGD ions binding to the adsorbent could be assumed to involve electrostatic interaction between cationic dyes and negatively charged $\mathrm{COO}^{-}$groups.

The results of the equilibrium $\mathrm{pH}$ (i.e, $\mathrm{pH}_{f}$ ) at different initial solution $\mathrm{pH}(2-10)$ ranged between 2.39 and 9.3 for $\mathrm{BGD} /$ Luffa system as shown in Figure 5. The $\mathrm{pH}_{f}$ values were higher than $\mathrm{pH}_{0}$ values for $\mathrm{pH}_{0}<8.0$ and this could be attributed to change in the structure of dye molecule.

\subsection{Effect of Initial Dye Concentration and Adsorption Kinet-} $i c s$. The rates of sorption of BGD by LFC at different initial BGD concentrations are shown in Figure 6. Uptake of BGD was rapid and equilibrium was attained within $180 \mathrm{~min}$. It was found that the amount BGD sorbed increased from 9.2 to $92.9 \mathrm{mg} / \mathrm{g}$ with increasing initial concentration from $20-200 \mathrm{mg} / \mathrm{L}$. The adsorption was initially rapid and then slowed down over time. This observation was ascribed to a large number of available binding sites for adsorption during the initial stage, and then the remaining sites were difficult 
TABLE 1: Kinetic parameters of sorption of BGD on LFC.

\begin{tabular}{lcccccccccccc}
\hline Initial conc. & \multicolumn{3}{c}{ Pseudo-first-order } & \multicolumn{3}{c}{ Pseudo-second-order } & \multicolumn{3}{c}{ Power function } & \multicolumn{2}{c}{ Simple Elovich } \\
$\mathrm{mg} / \mathrm{L}$ & $q_{e_{1}}$ & $k_{1} \times 10^{-2}$ & $r^{2}$ & $q_{e_{2}}$ & $k_{2}$ & $h_{0}$ & $r^{2}$ & $a$ & $b$ & $r^{2}$ & $A$ & $B$ \\
\hline 20 & 1.54 & 0.2303 & 0.820 & 9.621 & 0.132 & 12.20 & 0.999 & 8.79 & 0.016 & 0.920 & 8.80 & 0.799 \\
40 & 1.86 & 0.2303 & 0.794 & 19.230 & 0.097 & 35.87 & 1.000 & 17.78 & 0.014 & 0.911 & 17.78 & 1.462 \\
80 & 3.07 & 0.4606 & 0.747 & 40.000 & 0.057 & 91.20 & 1.000 & 35.73 & 0.015 & 0.916 & 35.70 & 3.001 \\
150 & 7.50 & 1.1515 & 0.966 & 76.920 & 0.011 & 65.08 & 0.999 & 63.39 & 0.025 & 0.977 & 63.26 & 9.046 \\
200 & 17.82 & 1.1612 & 0.916 & 100.000 & 0.004 & 40.00 & 0.999 & 70.15 & 0.051 & 0.967 & 69.51 & 22.48 \\
\hline
\end{tabular}

$k_{1}=\mathrm{min}^{-1}, q_{e_{1}}=\mathrm{mg} / \mathrm{g}, q_{e_{2}}=\mathrm{mg} / \mathrm{g}, k_{2}=\mathrm{g} / \mathrm{mg} / \mathrm{min}, B=\mathrm{g} / \mathrm{mg}, A=\mathrm{mg} / \mathrm{g} \mathrm{min}$.

to occupy due to repulsive forces between the dye molecules on the LFC and the bulk phase [39]. The results showed that the time taken to attain equilibrium was independent of the initial dye concentration. Similar profile has been reported in the literature for the effect of time and initial concentration for the removal of BGD by adsorbents like kaolin [19], bottom ash and deoiled soya [26], neem leaf powder [31], and modified peat-resin [40].

In order to explore the kinetics involved in dye sorption, the experimental data were fitted into four kinetic models including the pseudo-first-order equation [41], pseudosecond-order equation [42], power function [43], and simple Elovich [44].

The linear form of the pseudo-first-order kinetic is expressed as follows:

$$
\ln \left(q_{e}-q_{t}\right)=\ln q_{e}-k_{i} t
$$

where $q_{e}$ and $q_{t}$ are BGD adsorbed at equilibrium and time $t$, respectively $(\mathrm{mg} / \mathrm{g})$, and $k_{1}$ is the rate constant for the pseudofirst-order model $\left(\mathrm{min}^{-1}\right)$. The pseudo-first-order constant $k_{1}$ and the correlation coefficient, $r^{2}$, deduced from the kinetic data are presented in Table 1. The $r^{2}$ value was poor and ranged between 0.747 and 0.966 . A significant chi $\chi^{2}$ values were also obtained indicating the inapplicability of this model to the sorption process.

The pseudo-second-order kinetic model is represented by the following linear equation:

$$
\frac{t}{q_{t}}=\frac{1}{k_{2} q_{e}^{2}}+\frac{1}{q_{e} t}
$$

where $k_{2}$ is the rate constant for the pseudo-second-order model $\left(\mathrm{g}(\mathrm{mg} \mathrm{min})^{-1}\right)$, where $q_{e}, q_{t}$, and $t$ have the same meaning as explained above.

The initial sorption rate can be obtained from the pseudosecond-order linear plots as $q_{t} / t$ approaches zero:

$$
h_{0}=k_{2} q_{e}^{2},
$$

where $h_{0}=$ initial sorption rate.

Equation (3) can be rearranged to obtain [45] as follows:

$$
q_{t}=\frac{1}{1 / h_{0}+t / q_{e}} .
$$

The $r^{2}$ values for the pseudo-second-order kinetic model were close to 1.0 for all cases. Comparing $r^{2}$ and chi $\chi^{2}$ value for pseudo-first- and second-kinetic model (Table 1), it is obvious that for the entire adsorption period, the pseudosecond-order model fits the experimental data better than the pseudo-first-order model. It thus shows that the system under study was more appropriately described by the pseudosecond-order model. This indicates that the adsorption mechanism for BGD is chemisorptions, involving covalent forces through sharing or exchange of electrons between sorbent and sorbate [46].

The value of $h_{0}, q_{e}$, and $k_{2}$ along with $r^{2}$ for the pseudosecond-order models are shown in Table 1 . The value of $q_{e}$ increased with increase in the initial BGD concentration while $h_{0}$ increase from 12.20 to 91.20 and later decreased drastically to 40.00 with the increases in initial concentration of BGD. According to Ho and Mckay [47] if the dye uptake is chemically rate controlled, the pseudo-second-rate constant will be independent of particle diameter and flow rate will depend on concentration of the ions in solution.

Logarithm plots of pseudo-second-order constants, $k_{2}$, and $h_{0}$, versus $C_{0}$ of BGD concentration were made, and the plots were found to be straight line whose linear regression values $r^{2}$, in terms of $C_{0}$, were given as 0.992 and 0.946 , respectively [45].

Mathematical expressions were therefore drawn relating the two pseudo-second-order constants and initial concentration as follows:

$$
\begin{gathered}
k_{2}=-0.008 C_{0}^{-0.656}, \\
h_{0}=-4.228 C_{0}^{8.408} .
\end{gathered}
$$

Linear plots of $q_{e_{2}}, k_{2}$, and $h_{0}$ against initial concentration $\left(C_{0}\right)$ were regressed to obtain these values in terms of $C_{0}$ with high concentration coefficient. Each of these parameters can be expressed as a function of $C_{0}$ for BGD as reported by Ho and McKay [47];

$$
\begin{aligned}
q_{e} & =\frac{C_{0}}{E_{q} C_{0}+F_{q}}, \\
k_{2} & =\frac{C_{0}}{E_{k} C_{0}+F_{k}}, \\
h_{0} & =\frac{C_{0}}{E_{h} C_{0}+F_{h}},
\end{aligned}
$$

where $E_{q}, F_{q}, E_{k}, F_{k}, E_{h_{0}}$, and $F_{h_{0}}$ are constants related to the respective equations. The values for these constants are 
TABLE 2: Empirical parameters for predicted $q_{e}, k$, and $h_{0}$ from $C_{0}$ for BGD dye.

\begin{tabular}{lcccccccc}
\hline$E_{q}(\mathrm{~g} / \mathrm{mg})$ & $F_{q}(\mathrm{~g} \mathrm{~min} / \mathrm{L})$ & $r^{2}$ & $E_{k}(\mathrm{mg} \mathrm{min} / \mathrm{g})$ & $F_{k}\left(\mathrm{mg}^{2} \mathrm{~min} / \mathrm{gL}\right)$ & $r^{2}$ & $E_{h_{0}}(\mathrm{~g} \mathrm{~min} / \mathrm{mg})$ & $F_{h_{0}}(\mathrm{~g} \mathrm{~min} / \mathrm{L})$ & $r^{2}$ \\
\hline 0.507 & 0.594 & 0.946 & $16.0 \times 10^{-4}$ & 0.128 & 0.921 & 1.326 & 15.46 & 0.998 \\
\hline
\end{tabular}

TABLE 3: Error analysis for the kinetic data of the sorption of BGD on LFC.

\begin{tabular}{lcccccccc}
\hline $\begin{array}{l}\text { Initial } \\
\text { conc. }\end{array}$ & Pseudo-first & $q_{e}=q_{e}\left(1-e^{-k_{i} t}\right)$ & Pseudo-second & $q_{e}=t k_{2} q_{e}^{2} /\left(1+t k_{2} q_{e}\right)$ & Power function & \multicolumn{2}{c}{$q_{e}=a t^{b}$} & \multicolumn{2}{c}{ Simple Elovich $q_{e}=A+B \ln t$} \\
$(\mathrm{mg} / \mathrm{L})$ & $\chi^{2}$ & $r^{2}$ & $\chi^{2}$ & $r^{2}$ & $\chi^{2}$ & $r^{2}$ & $\chi^{2}$ \\
\hline 20 & 12.376 & 0.997 & $1.83 \times 10^{-4}$ & 0.999 & $5.28 \times 10^{-4}$ & 1.000 & 1.150 & $r^{2}$ \\
40 & 24.698 & 0.997 & $1.89 \times 10^{-4}$ & 1.000 & $3.55 \times 10^{-4}$ & 1.000 & 1.490 & 1.000 \\
80 & 12.985 & 0.987 & $2.39 \times 10^{-5}$ & 1.000 & $4.51 \times 10^{-4}$ & 1.000 & 3.19 & 1.000 \\
150 & 1.311 & 0.940 & $3.50 \times 10^{-3}$ & 0.999 & $1.26 \times 10^{-3}$ & 1.000 & 12.93 & 1.000 \\
200 & 0.294 & 0.910 & $2.06 \times 10^{-2}$ & 0.999 & $3.48 \times 10^{-3}$ & 1.000 & 47.71 & 1.000 \\
\hline
\end{tabular}

listed in Table 2. Hence the generalized predictive model for BGD sorbed at any contact time and initial concentration within the given range with relationship of $q_{e}, C_{0}$, and $t$ can be represented as follows by substituting the various values in $(10)$.

$$
\begin{aligned}
& \text { For BGD-LFC system [47]: } \\
& q_{t}=\frac{t}{1 /\left(1.326 C_{0}+15.46\right)+1 /\left(0.507 C_{0}+0.594\right) t}
\end{aligned}
$$

Equation (12) represents the generalized predictive model for BGD sorbed at any time and the initial BGD concentration within the given range.

To further establish the appropriate kinetic for BGD uptake, the experimental data was fitted again to power function and simple Elovich models.

The power function model is a modified form of the Freundlich equation and may be expressed as:

$$
\log q=\log a+b \log t
$$

while the simple Elovich [45] is expressed as:

$$
q=A+2.303 B \log t \text {. }
$$

The results obtained for the fitting of the kinetic models to explained data are presented in Table 1 and the error functions are presented in Table 3. For the pseudo-first-order kinetic and simple Elovich models, the predicted $q_{e}$ values were at variance coincident with the experimental $q_{e}$ values. The predicted $q_{e}$ values derived from pseudo-second-order and power function model agreed with the experimental $q_{e}$ data. The values $\chi^{2}$ of the error function were negligible for pseudo-second-order and power function model. This result indicates that the pseudo-second-order and power function model provided a high degree of correlation with the experimental data for the sorption of BGD by LFC.

3.4. Intra-Particle Diffusion Model. Intraparticle diffusion model based on the theory proposed by Weber and Morris which has been widely applied for sorption studies was applied to investigate the mechanism of the adsorption of

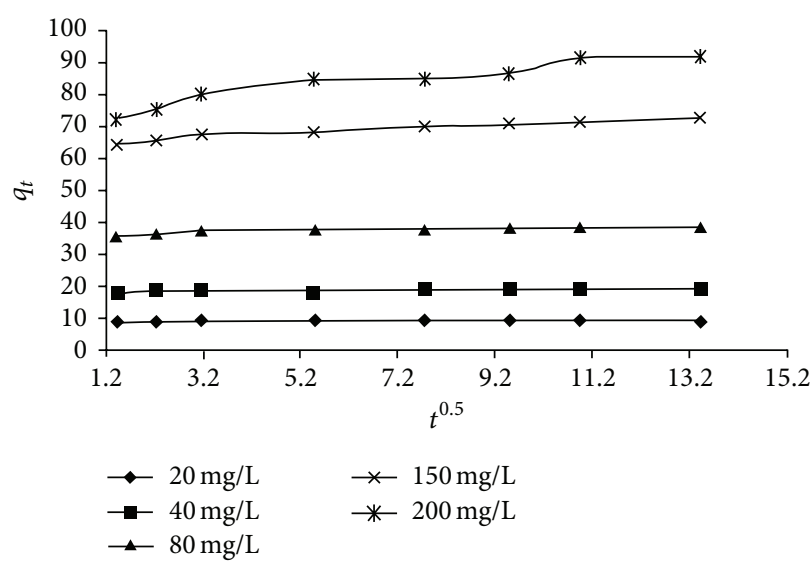

FIGURE 7: Plot of $q_{t}$ versus $t^{0.5}$ for the adsorption of BGD onto LFC.

BGD onto LFC. The intraparticle diffusion model is typically given as follows [48]:

$$
q_{t}=k_{\mathrm{id}} t^{0.5}+Z
$$

where $Z\left(\mathrm{mgg}^{-1}\right)$ is the intercept and $k_{\text {id }}\left(\mathrm{mgg}^{-1} \mathrm{~min}^{0.5}\right)$ is the intraparticle diffusion rate constant. Value of $k_{\mathrm{id}}$ was obtained from the slope of the linear plot of $q_{t}$ versus $t^{0.5}$ (Figure 7). Value of $Z$ as shown in Table 3 gives an idea about the thickness of the boundary layer [49]. The deviation from this theory signifies the difference between the rate of mass transfer in the initial and final stage of adsorption [50].

However, if the data exhibit multilinear plots, then two or more steps influence the sorption process. The first, sharper portion is attributed to the transport of the solute from bulk solution liquid film to the adsorbent exterior surface. The second linear portion is based on the diffusion across the liquid film surrounding the sorbent particle. The third portion is due to particle diffusion in the liquid contained in the pore and in the sorbate along the pore wall.

Figure 7 shows a representative $q_{t}$ versus $t^{0.5}$ plot for BGD adsorption onto LFC for $C_{0}=20,40,80,150$, and $200 \mathrm{mg} / \mathrm{L}$ at $30^{\circ} \mathrm{C}$. Observation from the figure shows that the plots were not linear over the whole time range; an indication that more 
TABLE 4: Macro- and micropores diffusion parameters for the sorption of BGD by LFC at different initial BG concentration (mg/L).

\begin{tabular}{lcccccc}
\hline Initial conc. $(\mathrm{mg} / \mathrm{L})$ & $k_{\mathrm{id}_{1}}$ & Intercept & $r^{2}$ & $k_{\mathrm{id}_{2}}$ & Intercept & $r^{2}$ \\
\hline 20 & 0.225 & 8.54 & 0.900 & 0.043 & 0.873 \\
40 & 0.478 & 17.17 & 0.901 & 0.074 & 0.04 & 18.26 \\
80 & 0.953 & 34.45 & 0.909 & 0.115 & 37.07 \\
150 & 1.918 & 61.68 & 0.992 & 0.498 & 65.97 \\
200 & 4.375 & 66.21 & 0.990 & 1.061 & 0.913 \\
\hline
\end{tabular}

TABLE 5: Liquid film diffusion parameters for the sorption of BGD by LFC at different initial BGD concentration (mg/L).

\begin{tabular}{|c|c|c|c|c|c|c|}
\hline \multirow{2}{*}{ Initial conc. (mg/L) } & \multicolumn{3}{|c|}{ First 30 mins } & \multicolumn{3}{|c|}{ Overall } \\
\hline & $k_{\mathrm{id}_{1}}$ & Intercept & $r^{2}$ & $k_{\mathrm{id}_{2}}$ & Intercept & $r^{2}$ \\
\hline 20 & 0.008 & 1.85 & 0.650 & 0.002 & 1.93 & 0.820 \\
\hline 40 & 0.011 & 2.28 & 0.465 & 0.004 & 2.38 & 0.794 \\
\hline 80 & 0.017 & 2.39 & 0.581 & 0.005 & 2.57 & 0.747 \\
\hline 150 & 0.017 & 2.19 & 0.718 & 0.011 & 2.28 & 0.966 \\
\hline 200 & 0.031 & 1.54 & 0.943 & 0.016 & 1.65 & 0.916 \\
\hline
\end{tabular}

than one process controlled the sorption process which are: surface sorption and intraparticle diffusion. For $C_{0}=$ 80,150 , and $200 \mathrm{mg} / \mathrm{L}$, there are two linear portions, the first straight portion depicting mesopore diffusion and the second represent micropore diffusion [51]. For $C_{0}=20$ and $40 \mathrm{mg} / \mathrm{L}$, there is only one linear portion depicting combined mesopore diffusion.

There is every possibility that the intraparticle diffusion of BGD into pores is the rate controlling step in the adsorption process. The amount of adsorbate and the driving force for BGD adsorption is less for $C_{0}=20$ and $40 \mathrm{mg} / \mathrm{L}$ as compared to that of $C_{0}=80,150$, and $200 \mathrm{mg} / \mathrm{L}$; hence, BGD adsorbed in mesopore only, and adsorption into mesopore is the rate-limiting step. For $C_{0}=80,150$, and $200 \mathrm{mg} / \mathrm{L}$, the driving force increases and overcomes the resistance for getting adsorbed into micropores; therefore, adsorption into micropores is the rate-limiting step for higher $C_{0}$. An observation from Table 4 shows that $K_{\mathrm{id}_{1}}$ and $K_{\mathrm{id}_{2}}$ are higher for higher $C_{0}$, which indicate enhanced diffusion of BGD through meso- and micropores at higher $C_{0}$. This is a contribution from higher driving force at higher $C_{0}$ [51]. Similar results have been reported for adsorption of BGD on saw dust [52], kaolin [19], and rice husk ash [32].

3.5. Liquid Film Diffusion Model. During sorption, the migration of dye molecules from bulk solution through liquid film to the exterior surface of adsorption may play an important role in determining the rate of the adsorption process. To predict the potential rate-controlling step, the adsorption dynamics of BGD onto LFC was investigated utilizing liquid film diffusion model (16) [53]:

$$
\ln (1-F)=-k_{\mathrm{fd}} t
$$

where $k_{\mathrm{fd}}\left(\mathrm{min}^{-1}\right)$ is the liquid film diffusion rate constants and $F=q_{t} / q_{e}$. The plot of $-\ln (l-F)$ versus $t$, for the liquid film diffusion, was tested over all concentration of study. The first 30 mins of sorption process yielded linear plot $\left(r^{2}=0.465-0.943\right)$ while the overall yielded $\left(r^{2}=0.747-\right.$ 0.966). The rate constant for liquid film diffusion, $k_{\mathrm{fd}}$, is in the range $8.0 \times 10^{-3}$ to $1.7 \times 10^{-2}$ for the first $30 \mathrm{~min}$ and $2.0 \times 10^{-3}$ to $1.6 \times 10^{-2}$ for overall (Table 5). The inability of the plot to pass through the origin (i.e., zero intercept) shows that the prediction of this model will have only limited applicability in the adsorption of BGD by LFC.

3.6. Adsorption Equilibrium Isotherm Study. The distribution of BGD between the liquid phase and the solid adsorbent phase is a measure of the position of equilibrium in the adsorption process and can be expressed by different equilibrium isotherm models. In this study, the Langmuir, Freundlich, and Temkin isotherms models were used to describe the adsorption process and the isotherm parameters obtained using these models are presented in Table 6.

The linear form of Langmuir's isotherm model is represented by the following equation:

$$
\frac{1}{q_{e}}=\frac{1}{Q_{0}}+\frac{1}{b Q_{0} C_{e}} .
$$

The values of monolayer sorption capacities, $Q_{0}(\mathrm{mg} / \mathrm{g})$, obtained from Langmuir plot of sorption decreased with increasing temperature. The magnitude of Langmuir constant, $b$, which is the sorption equilibrium constant $\left(\mathrm{dm}^{3} /\right.$ $\mathrm{mg}$ ), decreases as shown in Table 6. The decrease of $b$ as temperature increases confirms the exothermic nature of the adsorption [54]. The essential characteristics of the Langmuir isotherm, used to predict the adsorption efficiency, was expressed in terms of a dimensionless equilibrium parameter $R_{L}$, defined by the following equation [55]:

$$
R_{L}=\frac{1}{1+b C_{0}},
$$

where $C_{0}(\mathrm{mg} / \mathrm{L})$ is the highest initial concentration of the adsorbate. The value of $R_{L}$ indicates if the Langmuir isotherm is unfavorable $\left(R_{L}>1\right)$, linear $\left(R_{L}=1\right)$, favorable 
TABLE 6: Adsorption isotherm constants for BGD on LFC.

\begin{tabular}{lcccccccccc}
\hline \multirow{2}{*}{ Temperature $\left({ }^{\circ} \mathrm{C}\right)$} & \multicolumn{4}{c}{ Langmuir } & \multicolumn{3}{c}{ Freundlich } & \multicolumn{3}{c}{ Temkin } \\
& $Q_{0}$ & $b$ & $R^{2}$ & $R_{L} \times 10^{-3}$ & $K_{f}$ & $1 / n$ & $R^{2}$ & $B_{I}$ & $R^{2}$ \\
\hline 30 & 18.52 & 17.99 & 0.991 & 2.7 & 17.83 & 0.722 & 0.958 & 27.75 & 2.150 & 0.984 \\
40 & 8.85 & 28.21 & 0.963 & 1.7 & 2.42 & 1.212 & 0.972 & 28.39 & 1.014 & 0.931 \\
50 & 5.68 & 35.16 & 0.961 & 1.4 & 1.01 & 0.176 & 0.964 & 35.04 & 1.410 & 0.944 \\
60 & 8.50 & 5.16 & 0.998 & 9.4 & 7.01 & 0.952 & 0.928 & 58.06 & 1.070 & 0.987 \\
\hline
\end{tabular}

TABLE 7: Error analysis for isotherm models for the sorption of BGD on LFC.

\begin{tabular}{|c|c|c|c|}
\hline Initial conc. (mg/L) & $\begin{array}{c}\text { Langmuir; } q_{e}=Q_{L} b c_{e} /\left(1+b c_{e}\right) \\
\chi^{2}\end{array}$ & $\begin{array}{c}\text { Freundlich; } q_{e}=k_{f} c_{f}^{1 / n} \\
\chi^{2}\end{array}$ & $\begin{array}{c}\text { Tempkin; } q_{e}=(R T / b) \ln \left(K_{T} c_{e}\right) \\
\chi^{2}\end{array}$ \\
\hline 20 & 0.2664 & 0.3782 & 0.4525 \\
\hline 40 & 0.0009 & 0.1016 & 0.2386 \\
\hline 80 & 0.0008 & 1.0420 & 2.4264 \\
\hline 150 & 0.1251 & 2.2042 & 16.5165 \\
\hline 200 & 1.4370 & 4.1396 & 126.0713 \\
\hline
\end{tabular}

$\left(0<R_{L}<1\right)$, or irreversible $\left(R_{L}=0\right)$. The values of $R_{L}$ at $C_{0}$ $=200 \mathrm{mg} / \mathrm{L}$ in the present study were found to be $2.7 \times 10^{-3}$ at $303 \mathrm{~K}, 1.7 \times 10^{-3}$ at $313 \mathrm{~K}, 1.4 \times 10^{-3}$ at $323 \mathrm{~K}$, and $9.4 \times 10^{-3}$ at $333 \mathrm{~K}$ indicating that the adsorption of $\mathrm{BGD}$ on $\mathrm{LFC}$ is favorable.

The experimental data obtained was also tested with Freundlich isotherm. Freundlich isotherm assumes heterogeneity of adsorption surfaces. The equation is commonly expressed as follows [56]:

$$
\log q_{e}=\log K_{f}+\frac{1}{n} \log C_{e} .
$$

The values of the Freundlich constant, $K_{f}$ and $n$, related to adsorption capacity and sorption intensity, respectively, obtained from the plot of $\log q_{e}$ versus $\log C_{e}$ are presented in Table $6 . K_{f}$ is the Freundlich affinity coefficient, and $1 / n$ is the Freundlich linearity index. It can be found that the values of $K_{f}$ and $n$ decrease, indicating that adsorption is favorable at lower temperature predicting endothermic nature of the adsorption process. Experimental data was also fitted to Temkin isotherm.

The Temkin isotherm assumes that a decrease in the adsorption heat is linear and that the adsorption is characterized by a uniform distribution of binding energies. The Temkin linear form of isotherm is given by equation $[57,58]$ :

$$
q_{e}=B_{I} \ln A+B_{I} \ln C_{e} .
$$

$B_{I}=R T / b, T$ is the absolute temperature $(\mathrm{K})$, and $R$ is the universal gas constant $(8.314 \mathrm{~J} / \mathrm{molK}), A$ is the equilibrium binding constant $(\mathrm{L} / \mathrm{mg})$, and $B_{I}$ is related to the heat of adsorption. The Temkin constants were listed in Table 6. In order to assess the different isotherms and their ability to correlate the experimental results, the theoretical plots for each isotherm have been shown along with the experimental data for the sorption of BGD onto LFC (Figure 7). The $r^{2}$ and $\chi^{2}$ values were shown in Table 7 and the different isotherms correlated with the experimental depicted in Figure 8 confirmed that the sorption of BGD onto LFC was best described

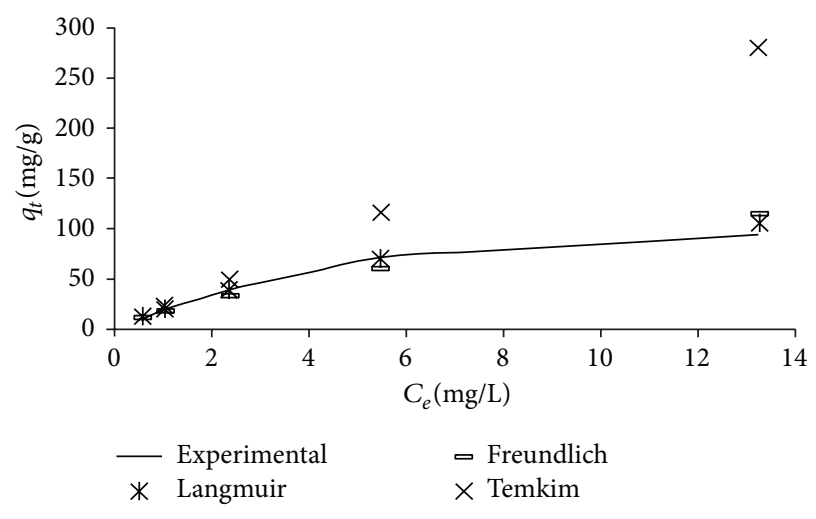

FIGURE 8: Comparison of experimental data with the theoretical data for equilibrium isotherm studies for the adsorption of BGD onto LFC.

by Langmuir isotherm model. The applicability of the Langmuir isotherm assumes that the entire adsorption sites are equivalent and there is no interaction between adsorbed species.

3.7. Estimation of Thermodynamic Parameter. To characterize the thermodynamic parameter of adsorption study means to determine Gibb's free energy, $\left(\Delta G^{0}, \mathrm{KJ} / \mathrm{mol}\right)$, enthalpy change $\left(\Delta H^{0}, \mathrm{KJ} / \mathrm{mol}\right)$, and entropy $\left(\Delta S^{0}, \mathrm{KJ} / \mathrm{mol} / \mathrm{K}\right)$ at a given reference temperature and to obtain $\Delta C_{p}$ so as to be able to predict the change of the above three parameters with temperature.

The Gibb's free energy change, $\Delta G$, of an association reaction is temperature dependent and best described by

$\Delta G^{0}=\Delta H_{(\mathrm{TR})}^{0}+\int_{\mathrm{TR}}^{T} \Delta C_{p} d T-T \Delta S_{(\mathrm{TR})}^{0}-T \int_{\mathrm{TR}}^{T} \Delta C_{p} d \ln T$. 
TABLE 8: Thermodynamic parameters for adsorption of BGD on LFC.

\begin{tabular}{|c|c|c|c|c|c|}
\hline Temperature $(\mathrm{K})$ & $\ln b$ & $-\Delta G^{0}\left(\mathrm{KJmol}^{-1}\right)$ & $\Delta H^{0}\left(\mathrm{KJmol}^{-1}\right)$ & $\Delta S^{0}\left(\mathrm{Jmol}^{-1} \mathrm{k}^{-1}\right)$ & $\Delta C_{p}\left(\mathrm{KJk}^{-1} \mathrm{~mol}^{-1}\right)$ \\
\hline 303 & 2.89 & 7.28 & 108.74 & 382.91 & -8.91 \\
\hline 313 & 3.34 & 8.69 & 19.62 & 90.46 & \\
\hline 323 & 3.56 & 9.56 & -82.27 & -225.09 & \\
\hline 333 & 1.64 & 4.53 & -197.03 & -578.08 & \\
\hline
\end{tabular}

$\Delta H^{0}$ and $\Delta S^{0}$ are the change in enthalpy and entropy, $\Delta C_{p}$ is the heat capacity change. TR is an appropriate reference temperature. In a simple term,

$$
\Delta G^{0}=\Delta H^{0}-T \Delta S^{0}
$$

which is related to sorption equilibrium constant $b$ at different temperature

$$
\Delta G^{0}=-R T \ln b
$$

Combining (22) and (23) above, we obtained

$$
\ln b=\frac{-\Delta G^{0}}{R T}=\frac{\Delta S^{0}}{R}-\frac{\Delta H^{0}}{R} \frac{1}{T} .
$$

$T$ is the absolute temperature $(\mathrm{K})$ and $R$ is universal gas constant $(8.314 \mathrm{~J} / \mathrm{molK})$. Thus, $\Delta H^{0}$ can be determined by the slope of the linear Van't Hoff plot, that is, as $\ln K$ versus $(1 / T)$, (Figure 9) using equation:

$$
\Delta H^{0}=\left[R \frac{d \ln K}{d(1 / T)}\right] .
$$

This method is an indirect method but an accurate method to calculate thermodynamics parameters at solid/solution interfaces. Enthalpies of adsorption are assumed to be invariable in relation to temperature. However, difficulties arise from this assumption. Taking into account the curvatures of Van't Hoff plots suggested in Figure 9, a second-order polynomial regression analysis of the Van't Hoff plots was used. The general equation of this type of analysis is $\ln b=$ $A+B \ln (T)+C / T$ where $A, B$, and $C$ are the regression coefficients. The $-\Delta H^{0} / R$ values were found from individual regressive function.

The polynomial regression produced better fits $\left(r^{2}\right.$ value from 0.990 to 0.999 ) in relation to the traditional Van't Hoff plot linear regression (less than 0.900). The curvatures indicate temperature dependence of $\Delta H^{0}$. Heat capacity, $\left(\Delta C_{p}\right)$, which is influenced by the number of accessible energy state, was determined over the range temperature of studies. As an important parameter, it controls the magnitude of $\Delta H^{0}$ and $\Delta S^{0}[59]$.

Considering temperature dependence of $\Delta H^{0}$, an equation can be written to represent nonzero temperature independent $\Delta C_{p}$ :

$$
\ln \frac{b_{d_{1}}}{b_{d_{2}}}=\frac{\Delta H_{i}-T_{i} \Delta C_{p}}{R}\left(\frac{1}{T_{1}}-\frac{1}{T_{2}}\right)+\frac{\Delta C_{p}}{R} \ln \frac{T_{2}}{T_{1}} .
$$

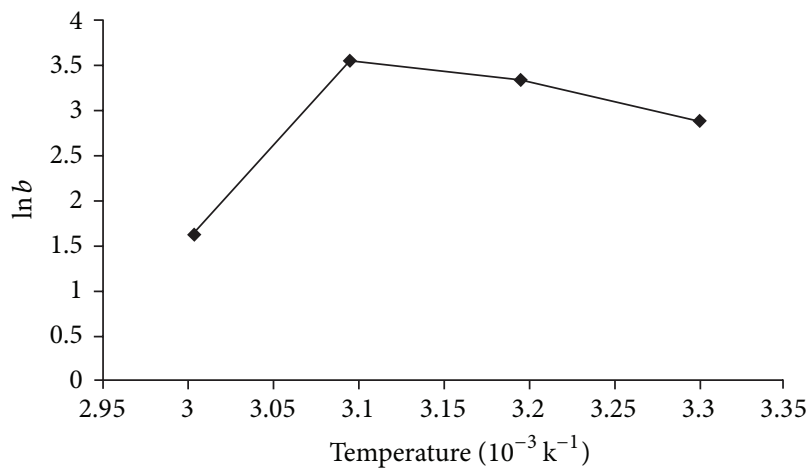

Figure 9: Van't Hoff plot of BGD dye adsorption by LFC.

The $\Delta C_{p}$ value was calculated in a simple manner, as

$$
\Delta C_{p}=\frac{d\left(\Delta H^{0}\right)}{d T}=\frac{T d\left(\Delta S^{0}\right)}{d T}=\frac{\Delta H_{T_{2}}^{0}-\Delta H_{T_{1}}^{0}}{\left(T_{2}-T_{1}\right)} .
$$

The thermodynamic parameters are shown in Table $8 . \Delta H^{0}$ is almost all positive and it decreases endothermically within the temperature range of $303 \mathrm{~K}$ to $333 \mathrm{~K}$. Explanation for the $\Delta H^{0}$ obtained within the temperature range of study is based on the fact that BGD and LFC surfaces are both solvated in water. In order for BGD to be adsorbed, they have to lose part of their hydration shell. The dehydration processes of the BGD and LFC surfaces require energy. In general the dehydration processes of the BGD and LFC supersede the exothermicity of the adsorption processes. Overall, it may be assumed that the removal of water from BGD and LFC surfaces is essentially an endothermic processes; this process exceeds that of exothermicity provided by the heat of adsorption as observed in this study. Indication from Table 8 shows that the negative value of $\Delta C_{p}$ couple with favorable positive entropy changes signifies hydrophobic interaction [59]. The negative value of $\Delta G^{0}$ over all temperature of studies indicates the spontaneous and feasible nature of the adsorption process and that binding of an adsorbate in solution is favored.

The positive $\Delta S^{0}$ values indicate an increase in disorderliness while negative $\Delta S^{0}$ value shows decrease in disorderliness. For the interaction of BGD with LFC, $\Delta S^{0}$ decrease positively; thus, from thermodynamic point of view entropy seems to be the driving force of adsorption [60].

3.8. Mechanism of Adsorption. BGD dye molecule can react with carbonyl and hydroxyl groups available on the surface of LFC. Comparing FTIR before and after adsorption, the peak at $3423 \mathrm{~cm}^{-1}$ from $-\mathrm{OH}$ remained unchanged but increased 
in intensity after adsorption suggesting that $-\mathrm{OH}$ group may bind with the immonium ion of the BGD molecule via hydrogen bonding which accounts for the emergence of the new peak at $3346 \mathrm{~cm}^{-1}$. The intensity of the peak at $1737 \mathrm{~cm}^{-1}$ assigned to carbonyl group of carboxylic acid decreased while the wavelength shifts to lower wave number after adsorption of BGD, indicating electrostatic interaction between the positively charged nitrogen moiety of the BGD dye molecule and the -COOH group of LFC.

\section{Conclusion}

LFC, a lignocellulosic material, was used as adsorbent to remove $\mathrm{BGD}$ from aqueous solution via batch experimental method. The kinetic studies were performed and the result obtained was fitted to pseudo-first-order, pseudo-second order, power function, and simple Elovich models. Both the pseudo-second-order and power function kinetic models provided excellent data fitting based on the statistical coefficient and chi-square error analysis. The equilibrium data showed that the experimental data correlated reasonably with the Langmuir isotherm model. Nonzero heat capacities term $\Delta C_{p}$ was obtained with the emergence of the plot of $\ln b$ versus $1 / T$ and the negative $\Delta C_{p}$ shown in this study indicates absence of thermal dehydration, stable species in solution. Negative value of $\Delta G^{0}$ suggests spontaneity and feasibility of adsorption process while the positive $\Delta S^{0}$ predicted that entropy is the driving force adsorption of BGD onto LFC.

\section{Conflict of Interests}

The authors declare that there is no conflict of interests regarding the publication of this paper.

\section{References}

[1] C. I. Pearce, J. R. Lloyd, and J. T. Guthrie, "The removal of colour from textile wastewater using whole bacterial cells: a review," Dyes and Pigments, vol. 58, no. 3, pp. 179-196, 2003.

[2] A. R. Cestari, E. F. S. Vieira, G. S. Vieira, and L. E. Almeida, “The removal of anionic dyes from aqueous solutions in the presence of anionic surfactant using aminopropylsilica-A kinetic study," Journal of Hazardous Materials, vol. 138, no. 1, pp. 133-141, 2006.

[3] Q. J. Qian, H. Z. Xiao, Y. X. Xiang, and Z. R. Tie, "Adsorptive removal of cationic dyes from aqueous solutions using graphite oxide," Journal of Adsorption Science and Technology, vol. 30, no. 5, pp. 437-447, 2012.

[4] T. K. Sen, S. Afroze, and H. M. Ang, "Equilibrium, kinetics and mechanism of removal of methylene blue from aqueous solution by adsorption onto pine cone biomass of Pinus radiata," Water, Air, and Soil Pollution, vol. 218, no. 1-4, pp. 499-515, 2011.

[5] T. Akar, A. S. Ozcan, S. Tunali, and A. Ozcan, "Biosorption of a textile dye (Acid Blue 40) by cone biomass of Thuja orientalis: estimation of equilibrium, thermodynamic and kinetic parameters," Bioresource Technology, vol. 99, no. 8, pp. 3057-3065, 2008.

[6] M. J. Pollock, "Neutralizing dyehouse wastes with flue gases and decolorizing with fly ash," The American Dyestuff Reporter, vol. 62, no. 8, pp. 21-23, 1973.
[7] M. K. Purkait, A. Maiti, S. DasGupta, and S. De, "Removal of congo red using activated carbon and its regeneration," Journal of Hazardous Materials, vol. 145, no. 1-2, pp. 287-295, 2007.

[8] M. G. Eilbeck, Chemical Process in Water Waste Treatment, John Wiley \& Sons, Chichester, UK, 1985.

[9] M. K. Purkait, S. DasGupta, and S. De, "Micellar enhanced ultrafiltration of eosin dye using hexadecyl pyridinium chloride," Journal of Hazardous Materials, vol. 136, no. 3, pp. 972977, 2006.

[10] M. K. Purkait, S. DasGupta, and S. De, "Removal of dye from waste water using micellar enhanced ultra fitrationn and recovery of surfactant," Journal of Separation and Purification Technology, vol. 37, pp. 81-92, 2003.

[11] S. Chakraborty, M. K. Purkait, S. DasGupta, S. De, and J. K. Basu, "Nanofiltration of textile plant effluent for color removal and reduction in COD," Separation and Purification Technology, vol. 31, no. 2, pp. 141-151, 2003.

[12] M. Mohammadi, A. J. Hassani, A. R. Mohamed, and G. D. Najafpour, "Removal of rhodamine B from aqueous solution using palm shell-based activated carbon: adsorption and kinetic studies," Journal of Chemical and Engineering Data, vol. 55, no. 12, pp. 5777-5785, 2010.

[13] G. Crini, "Non-conventional low-cost adsorbents for dye removal: a review," Bioresource Technology, vol. 97, no. 9, pp. 1061-1085, 2006.

[14] M. Doğan, Y. Özdemir, and M. Alkan, "Adsorption kinetics and mechanism of cationic methyl violet and methylene blue dyes onto sepiolite," Dyes and Pigments, vol. 75, no. 3, pp. 701-713, 2007.

[15] C. Chen, M. Zhang, Q. Guan, and W. Li, "Kinetic and thermodynamic studies on the adsorption of xylenol orange onto MIL101(Cr)," Chemical Engineering Journal, vol. 183, pp. 60-67, 2012.

[16] Z. Ioannou, C. Karasavvidis, A. Dimirkou, and V. Antoniadis, "Adsorption of methylene blue and methyl red dye from aqueous solutions onto modified zeolite," Journal of Water Science and Technology, vol. 67, no. 5, pp. 1129-1136, 2013.

[17] N. A. Oladoja, C. O. Aboluwoye, and A. O. Akinkugbe, "Evaluation of loofah as a sorbent in the decolorization of basic dye contaminated aqueous system," Industrial and Engineering Chemistry Research, vol. 48, no. 6, pp. 2786-2794, 2009.

[18] J. C. Liu, S. Ma, and L. J. Zang, "Preparation and characterization of ammonium-functionalized silica nano particle as new adsorbent to remove methyl orange from aqueous solution," Journal of Applied Surface Science, vol. 265, pp. 393-398, 2013.

[19] B. K. Nandi, A. Goswami, and M. K. Purkait, "Adsorption characteristics of brilliant green dye on kaolin," Journal of Hazardous Materials, vol. 161, no. 1, pp. 387-395, 2009.

[20] I. D. Mall, V. C. Srivastava, and N. K. Agarwal, "Removal of Orange-G and Methyl Violet dyes by adsorption onto bagasse fly ash-kinetic study and equilibrium isotherm analyses," Dyes and Pigments, vol. 69, no. 3, pp. 210-223, 2006.

[21] R. Gong, Y. Ding, M. Li, C. Yang, H. Liu, and Y. Sun, "Utilization of powdered peanut hull as biosorbent for removal of anionic dyes from aqueous solution," Dyes and Pigments, vol. 64, no. 3 , pp. 187-192, 2005.

[22] A. Z. Aroguz, J. Gulen, and R. H. Evers, "Adsorption of methylene blue from aqueous solution on pyrolyzed petrified sediment," Bioresource Technology, vol. 99, no. 6, pp. 1503-1508, 2008.

[23] N. A. Oladoja and A. K. Akinlabi, "Congo red biosorption on palm kernel seed coat," Industrial and Engineering Chemistry Research, vol. 48, no. 13, pp. 6188-6196, 2009. 
[24] S. Dawood and T. K. Sen, "Removal of anionic dye Congo red from aqueous solution by raw pine and acid-treated pine cone powder as adsorbent: equilibrium, thermodynamic, kinetics, mechanism and process design," Water Research, vol. 46, no. 6, pp. 1933-1946, 2012.

[25] R. L. M. Allen, Colour Chemistry, Appleton-Century Crofts Education Division, 1971.

[26] A. Mittal, D. Kaur, and J. Mittal, "Applicability of waste materials-bottom ash and deoiled soya-as adsorbents for the removal and recovery of a hazardous dye, brilliant green," Journal of Colloid and Interface Science, vol. 326, no. 1, pp. 8-17, 2008.

[27] Y. Kismir and A. Z. Aroguz, "Adsorption characteristics of the hazardous dye brilliant green on Saklıkent mud," Chemical Engineering Journal, vol. 172, no. 1, pp. 199-206, 2011.

[28] H. W. Yeung, W. W. Li, and T. B. Ng, "Isolation of a ribosomeinactivating and abortifacient protein from seeds of Luffa acutangula," International Journal of Peptide and Protein Research, vol. 38, no. 1, pp. 15-19, 1991.

[29] H. Demir, A. Top, D. Balköse, and S. Ülkü, "Dye adsorption behavior of Luffa cylindrica fibers," Journal of Hazardous Materials, vol. 153, no. 1-2, pp. 389-394, 2008.

[30] O. Abdelwahab, "Evaluation of the use of loofa activated carbons as potential adsorbents for aqueous solutions containing dye," Desalination, vol. 222, no. 1-3, pp. 357-367, 2008.

[31] K. G. Bhattacharyya and A. Sarma, "Adsorption characteristics of the dye, brilliant green, on neem leaf powder," Dyes and Pigments, vol. 57, no. 3, pp. 211-222, 2003.

[32] V. S. Mane, I. D. Mall, and V. C. Srivastava, "Kinetic and equilibrium isotherm studies for the adsorptive removal of brilliant green dye from aqueous solution by rice husk ash," Journal of Environmental Management, vol. 84, no. 4, pp. 390-400, 2007.

[33] L. S. Balistrieri and J. W. Murray, "The surface chemistry of goethite (alpha-FeOOH) in major ion seawater," The American Journal of Science, vol. 281, no. 6, pp. 788-806, 1981.

[34] A. I. Vogel, Text Book of Practical Organic Chemistry, Longman, London, UK, 1970.

[35] V. O. A. Tanobe, T. H. D. Sydenstricker, M. Munaro, and S. C. Amico, "A comprehensive characterization of chemically treated Brazilian sponge-gourds (Luffa cylindrica)," Polymer Testing, vol. 24, no. 4, pp. 474-482, 2005.

[36] M. A. H. Hassan, L. M. A. Fayoumi, and M. M. Jamal, "Kinetic study of the discoloration of triphenylmethane dyes as a function of $\mathrm{pH}$, salt effect," Journal of the University of Chemical Technology and Metallurgy, vol. 46, pp. 395-400, 2011.

[37] J. D. Roberts and M. C. Caserio, Basic Principle of Organic Chemistry, W. A. Benjamin, Inc., Menlo Park, Calif, USA, 2nd edition, 1977.

[38] O. K. Júnior, L. V. A. Gurgel, R. P. de Freitas, and L. F. Gil, "Adsorption of $\mathrm{Cu}(\mathrm{II}), \mathrm{Cd}(\mathrm{II})$, and $\mathrm{Pb}$ (II) from aqueous single metal solutions by mercerized cellulose and mercerized sugarcane bagasse chemically modified with EDTA dianhydride (EDTAD)," Carbohydrate Polymers, vol. 77, no. 3, pp. 643-650, 2009.

[39] A. C. A. da Costa, L. M. S. de Mesquita, and J. Tornovsky, "Batch and continuous heavy metals biosorption by a brown seaweed from a zinc-producing plant," Minerals Engineering, vol. 9, no. 8, pp. 811-824, 1996.

[40] Q. Sun and L. Yang, "The adsorption of basic dyes from aqueous solution on modified peat-resin particle," Water Research, vol. 37, no. 7, pp. 1535-1544, 2003.
[41] S. Lanregren, "About the theory of so-called adsorption of soluble substances," Kungliga Svenska Vetenskapsakademiens Handlingar, vol. 24, no. 4, pp. 1-39, 1889.

[42] Y. S. Ho, "Review of second-order models for adsorption systems," Journal of Hazardous Materials, vol. 136, no. 3, pp. 681689, 2006.

[43] L. Zeng, X. M. Li, and J. D. Liu, "Adsorptive removal of phosphate from aqueous solutions using iron oxide tailings," Water Research, vol. 38, no. 5, pp. 1318-1326, 2004.

[44] J. Zeldowitsch, "Über den mechanismus der katalytischen oxydation von $\mathrm{CO}$ an $\mathrm{MnO}_{2}$," Acta Physicochimica URSS, vol. 1, pp. 449-464, 1934.

[45] Y. S. Ho and G. McKay, "Sorption of dye from aqueous solution by peat," Chemical Engineering Journal, vol. 70, no. 2, pp. 115124, 1998.

[46] Y. S. Ho and A. E. Ofomaja, "Pseudo-second-order model for lead ion sorption from aqueous solutions onto palm kernel fiber," Journal of Hazardous Materials, vol. 129, no. 1-3, pp. 137142, 2006.

[47] Y. S. Ho and G. McKay, "A kinetic study of dye sorption by biosorbent waste product pith," Resources, Conservation and Recycling, vol. 25, no. 3-4, pp. 171-193, 1999.

[48] W. J. Weber and J. C. Morris, "Kinetics of adsorption on carbon from solution," Journal of Sanitary Engineering Division, vol. 89, pp. 31-59, 1963.

[49] N. Kannan and M. M. Sundaram, "Kinetics and mechanism of removal of methylene blue by adsorption on various carbons-a comparative study," Dyes and Pigments, vol. 51, no. 1, pp. 25-40, 2001.

[50] K. K. Panday, G. Prasad, and V. N. Singh, "Copper(II) removal from aqueous solutions by fly ash," Water Research, vol. 19, no. 7, pp. 869-873, 1985.

[51] U. R. Lakshmi, V. C. Srivastava, I. D. Mall, and D. H. Lataye, "Rice husk ash as an effective adsorbent: evaluation of adsorptive characteristics for indigo carmine dye," Journal of Environmental Management, vol. 90, no. 2, pp. 710-720, 2009.

[52] V. S. Mane and P. V. V. Babu, "Studies on the adsorption of brilliant green dye from aqueous solution onto low-cost $\mathrm{NaOH}$ treated saw dust," Desalination, vol. 273, no. 2-3, pp. 321-329, 2011.

[53] G. E. Boyd, A. W. Adamson, and L. S. Myers Jr., "The exchange adsorption of ions from aqueous solutions by organic zeolites. II. Kinetics," Journal of the American Chemical Society, vol. 69, no. 11, pp. 2836-2848, 1947.

[54] Y. S. Ho, T. H. Chiang, and Y. M. Hsueh, "Removal of basic dye from aqueous solution using tree fern as a biosorbent," Process Biochemistry, vol. 40, no. 1, pp. 119-124, 2005.

[55] K. R. Hall, L. C. Eagleton, A. Acrivos, and T. Vermeulen, "Poreand solid-diffusion kinetics in fixed-bed adsorption under constant-pattern conditions," Industrial and Engineering Chemistry Fundamentals, vol. 5, no. 2, pp. 212-223, 1966.

[56] H. M. F. Freundlich, "Ube die adsorption in losurgen," Zeitschrift für Physikalische Chemie A, vol. 57, pp. 385-470, 1906.

[57] V. S. Mane, I. D. Mall, and V. C. Srivastava, "Use of bagasse fly ash as an adsorbent for the removal of brilliant green dye from aqueous solution," Dyes and Pigments, vol. 73, no. 3, pp. 269278, 2007.

[58] I. A. W. Tan, B. H. Hameed, and A. L. Ahmad, "Equilibrium and kinetic studies on basic dye adsorption by oil palm fibre activated carbon," Chemical Engineering Journal, vol. 127, no. 1-3, pp. 111-119, 2007. 
[59] G. A. Holdgate and W. H. J. Ward, "Measurements of binding thermodynamics in drug discovery," Drug Discovery Today, vol. 10, no. 22, pp. 1543-1550, 2005.

[60] P. V. Messina and P. C. Schulz, "Adsorption of reactive dyes on titania-silica mesoporous materials," Journal of Colloid and Interface Science, vol. 299, no. 1, pp. 305-320, 2006. 

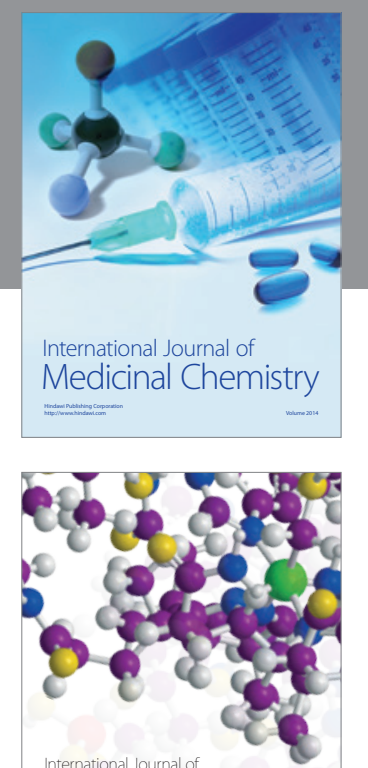

\section{Carbohydrate} Chemistry

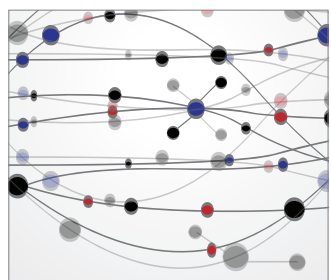

The Scientific World Journal
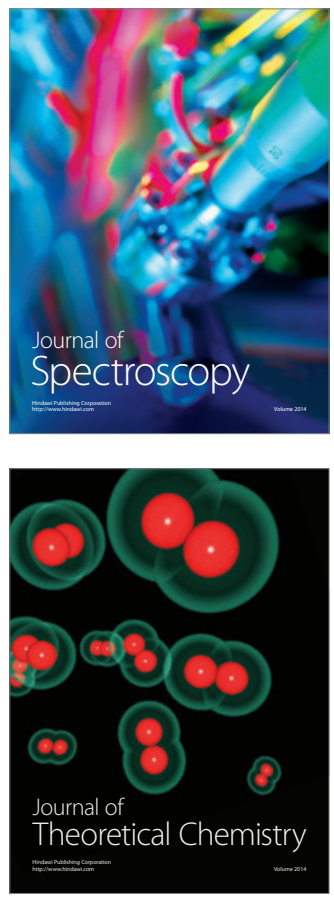
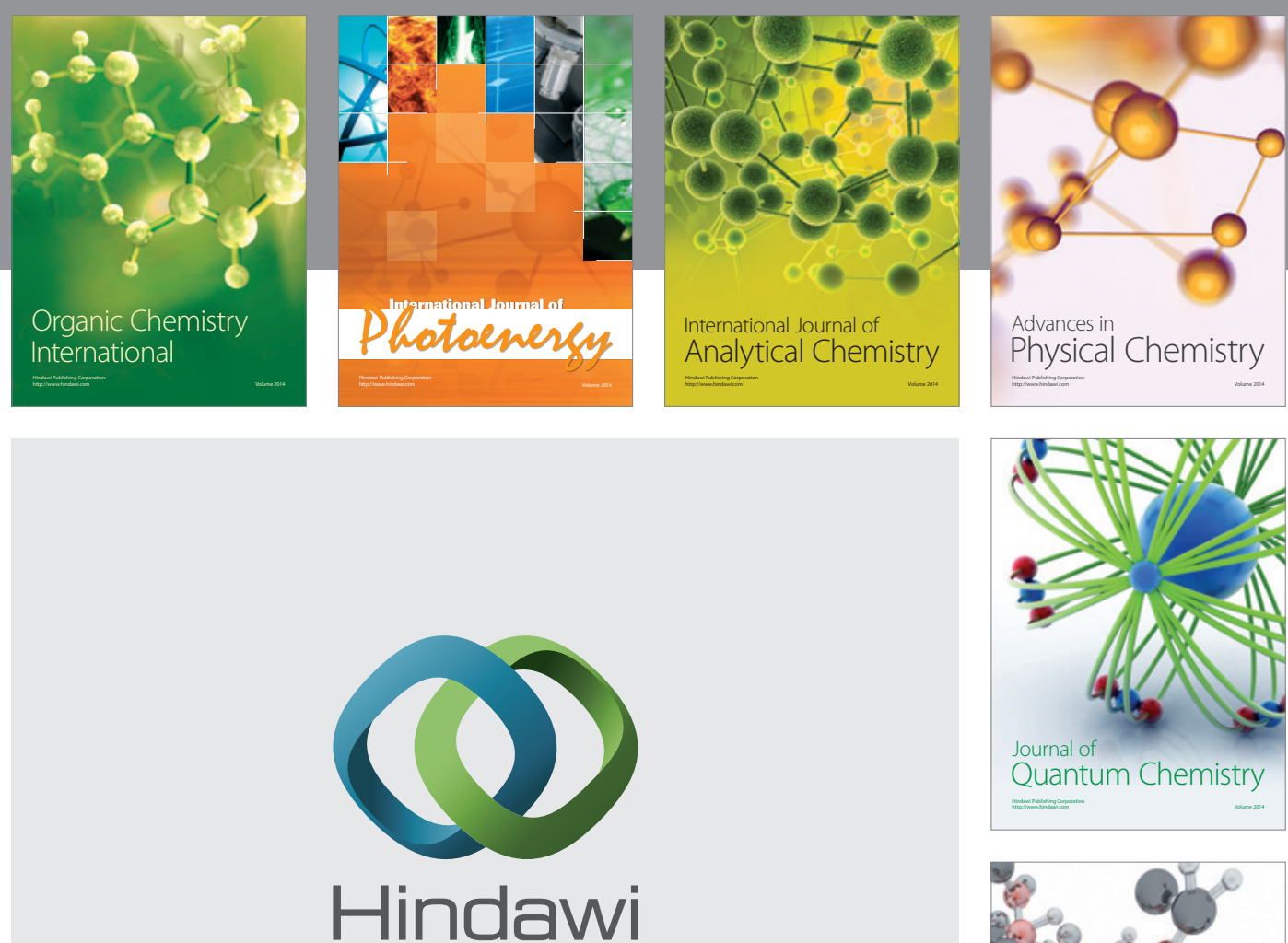

Submit your manuscripts at

http://www.hindawi.com

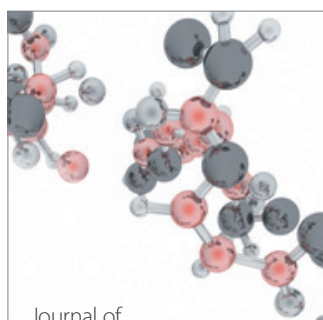

Analytical Methods

in Chemistry

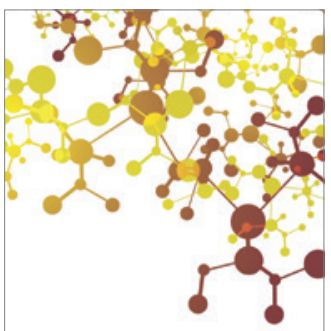

Journal of

Applied Chemistry

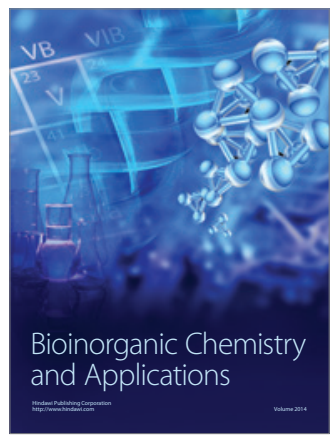

Inorganic Chemistry
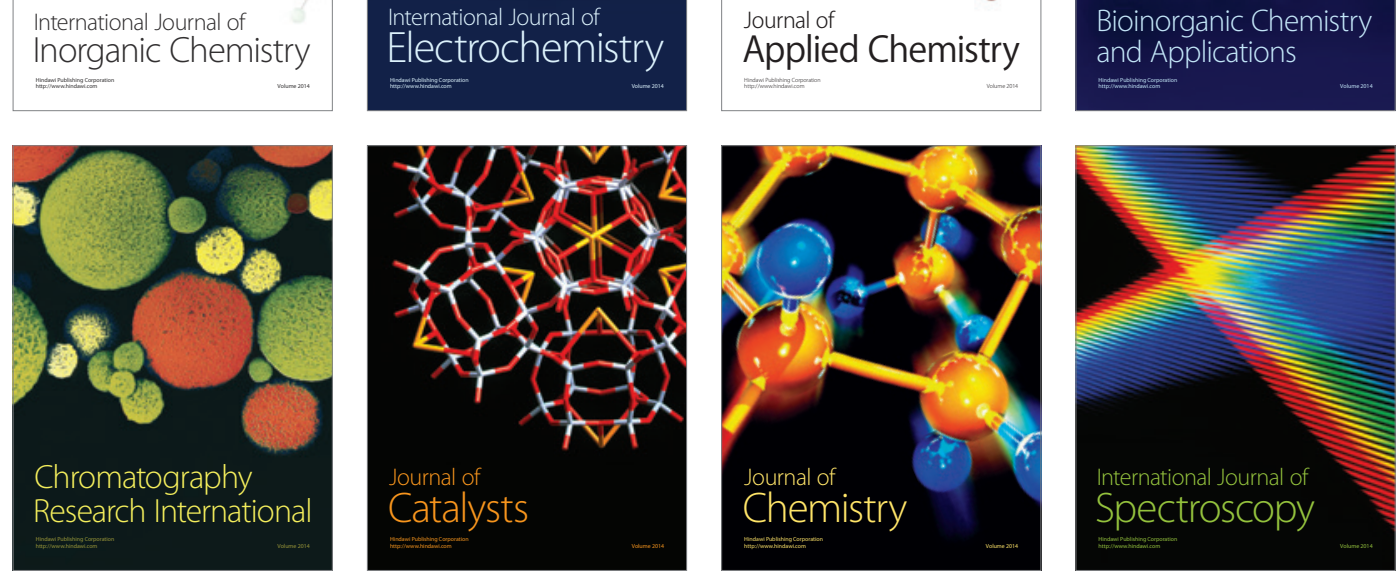